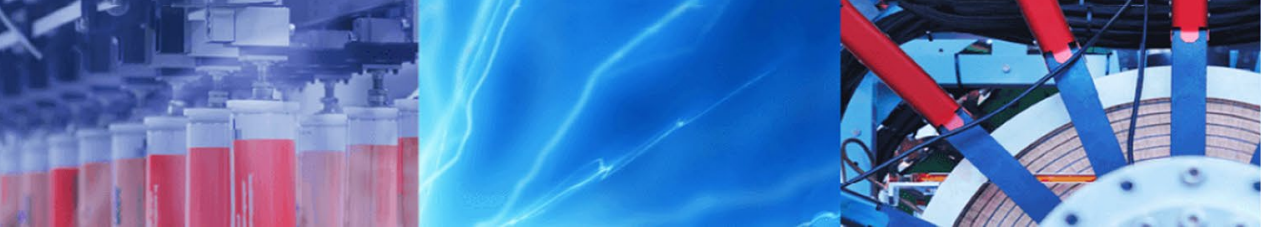

Research Article

\title{
Intrinsic adsorption properties of raw coal fly ash for quinoline from aqueous solution: kinetic and equilibrium studies
}

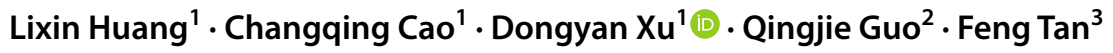

(c) Springer Nature Switzerland AG 2019

\begin{abstract}
Fly ash and quinoline are two major waste materials produced by the large scale utilization of coal. This study describes the investigation into the intrinsic adsorption properties of raw coal fly ash toward quinoline in the aqueous solution. The adsorbent was characterized using XRF, SEM, BET, and XRD. Batch experiments were performed to detect the influences of adsorption conditions on the adsorption capacity of coal fly ash. The results show that the amounts of adsorbed quinoline increase with the increment of initial quinoline concentration and contact time. The potential adsorption mechanism and rate-determining steps were illustrated by analyzing adsorption equilibrium with Langmuir, Freundlich and RedlichPeterson isotherm models and correlating the experimental results with several kinetic models. It was noticeable that the adsorption process experiences an initial rapid and a subsequent slow uptake stages. Moreover, the adsorption of quinoline on coal fly ash complies with the pseudo-second-order kinetics, and the adsorption isotherm is well described by the Langmuir adsorption model.
\end{abstract}

Keywords Adsorption · Quinoline · Kinetics · Coal fly ash · Wastewater

\section{Introduction}

During the past decades, the urgent situation with scarcity of domestic crude oil and natural gas as well as relative abundance of coal resource has significantly boosted the development of coal-based chemical industries in China [1]. However, these industries inevitably produce massive coking wastewaters during coal gasification, coal gas purification and by-product recovery processes [2, 3]. In general, the coking wastewater contains plenty of nonbiodegradable and refractory organic pollutants that are highly concentrated, toxic and carcinogenic [4]. Direct discharge of these coking wastewaters can cause serious natural water pollution and may have long-term environmental and ecological impacts.
Quinoline is a typical $\mathrm{N}$-heterocyclic aromatic compound that is present in the coal gasification wastewater. Nowadays, it remains challenging to achieve effective removal of quinoline from wastewater due to their relatively high aqueous solubility and low biodegradability $[2,5]$. Up to date, numerous investigations have been undertaken on the withdrawal of quinoline from wastewater via a variety of biological, physical and chemical methods, such as biological treatment [6], adsorption [7], wet oxidation and catalytic wet oxidation [8, 9], Fenton-like [10], photocatalysis [5], and ozonation [11] etc. Largely owing to its simplicity and widely available adsorbent materials, adsorption has been considered as one of the most promising alternatives to the treatment of organic pollutants in aqueous solutions. Activated carbon has long been regarded as an ideal adsorbent. However, the high cost of activated carbon has stimulated

$\triangle$ Dongyan Xu, xdy0156@qust.edu.cn | 'State Key Laboratory Base of Eco-chemical Engineering, College of Chemical Engineering, Qingdao University of Science and Technology, Qingdao 266042, People's Republic of China. ${ }^{2}$ State Key Laboratory of High-efficiency Coal Utilization and Green Chemical Engineering, College of Chemistry and Chemical Engineering, Ningxia University, Yinchuan 750021, People's Republic of China. ${ }^{3}$ Key Laboratory of Industrial Ecology and Environmental Engineering (Ministry of Education), School of Environmental Science and Technology, Dalian University of Technology, Dalian 116024, People's Republic of China. 
the interest in replacing it with various solid waste materials [12].

The utilization of coal also produces a solid waste, coal fly ash (CFA), which is a major by-product of thermal power plants all over the world [13]. The amount of annually discharged CFA is enormous and its improper disposal has become a serious environmental concern [14]. From the perspective of physicochemical characteristics, CFA is favorable for use as an adsorbent for treating various organic pollutants from an aqueous solution [15]. During the past decades, many researchers have evaluated the performance of CFA as cheap adsorbent for handling various organic contaminants including phenolic compounds [16, 17], dyes [18, 19], lignin [20], tannin [21], ciprofloxacin [22], etc. However, the adsorption performance strongly depends on the activation methods of CFA $[4,18]$. These activation processes usually involve chemical treatments of CFA with strong acids or bases that can inevitably lead to a secondary pollution, making it more attractive to use raw CFA directly. Until now, the scientific researches regarding direct utilization of raw CFA for treating coal gasification wastewater are very rare, and more detailed evaluations are needed for better illustrating the intrinsic adsorption properties of raw CFA for quinoline.

In this work, we investigate the intrinsic adsorption properties of the as-received CFA for quinoline from aqueous solution. The dependence of adsorption on CFA dosage, initial quinoline concentration and contact time were systematically studied in batch mode. We adopted the most widely used adsorption isotherms and kinetic models to fit the experimental data and discussed the potential adsorption mechanism.

\section{Experimental}

\subsection{Material and characterization}

The CFA was obtained from Qingdao Thermal Power Plant, China. The CFA was used without further treatment. Quinoline was purchased from Tianjin Beilian Fine Chemicals Development Co., Ltd., China. The composition of the raw CFA was determined by $\mathrm{X}$-ray fluorescence spectrometry (XRF) in a Bruker S4 Pioneer spectrophotometer. The morphology of the CFA was measured with scanning electron microscopy (SEM, JSM $6700 \mathrm{~F}$, operating at 8 kV). Powder $X$-ray diffraction (XRD) pattern of the fly ash was recorded on a D/max-2500/PC X-ray diffractometer (Rigaku, Japan) with a $\mathrm{Cu}$ Ka radiation source. The $\mathrm{N}_{2}$ adsorption-desorption isotherms were carried out at $77 \mathrm{~K}$ on a surface area analyzer
(Micromeritics, ASAP2020, USA). The surface area was estimated by the Brunauer-Emmett-Teller (BET) method.

\subsection{Adsorption experiments}

Adsorption of quinoline on CFA was conducted by directly mixing the CFA with standard quinoline solution. In a typical adsorption experiment, $0.25 \mathrm{~g}$ of CFA was added to $50 \mathrm{~mL}$ of quinoline solution with initial concentration of $50 \mathrm{mg} / \mathrm{L}$ and maintained for the time corresponding to the analysis. All the adsorption experiments were conducted at the initial $\mathrm{pH}$ of quinoline solution $(7 \pm 0.2)$. Then, the CFA was filtered with a $0.45 \mu \mathrm{m}$ polytetrafluoroethylene syringe membrane filter and the filtrate solution was analyzed for obtaining the remaining concentration of quinoline. The kinetic experiments were carried out by varying the initial quinoline concentration $(20-100 \mathrm{mg} / \mathrm{L})$, solution temperature $\left(25-45^{\circ} \mathrm{C}\right)$ and adsorbent dosage (2-10 $\mathrm{g} / \mathrm{L})$, respectively. All of the tests were carried out in duplicate. The analysis of quinoline concentration was performed by using an UV-vis spectrophotometer (Yoke).

The equilibrium adsorption capacity $\left(q_{e}\right)$ and timedependent adsorption capacity $\left(q_{t}\right)$ are calculated from the following equations, respectively:

$q_{e}=\frac{V\left(C_{0}-C_{e}\right)}{m}$

$q_{t}=\frac{V\left(C_{0}-C_{t}\right)}{m}$

where $C_{0}, C_{t}$ and $C_{e}$ are the initial, time-dependent and equilibrium quinoline concentrations $(\mathrm{mg} / \mathrm{L})$, respectively. $V(\mathrm{~L})$ is the volume of solution and $m(\mathrm{~g})$ is the adsorbent amount.

\section{Results and discussion}

\subsection{Characterization of CFA}

The properties of the CFA sample are as shown in Table 1 . $\mathrm{SiO}_{2}$ and $\mathrm{Al}_{2} \mathrm{O}_{3}$ are the main components with a total content of $58.8 \mathrm{wt} \%$. The specific surface area and pore volume of the CFA obtained from the $\mathrm{N}_{2}$ equilibrium adsorption isotherms are $8.84 \mathrm{~m}^{2} / \mathrm{g}$ and $0.016 \mathrm{~cm}^{3} / \mathrm{g}$, respectively, as shown in Table 2. The XRD pattern of the as-received CFA sample is presented in Fig. 1. The major crystalline phases were identified to be quartz $\left(\mathrm{SiO}_{2}\right)$, mullite $\left(3 \mathrm{Al}_{2} \mathrm{O}_{3} \mathrm{SiO}_{2}\right)$,
Table 1 Chemical compositions of coal fly ash (wt\%)

\begin{tabular}{llllllll}
\hline Composition & $\mathrm{SiO}_{2}$ & $\mathrm{Al}_{2} \mathrm{O}_{3}$ & $\mathrm{CaO}$ & $\mathrm{Fe}_{2} \mathrm{O}_{3}$ & $\mathrm{SO}_{3}$ & $\mathrm{Na}_{2} \mathrm{O}$ & Others \\
\hline Percentage & 41.07 & 17.69 & 13.44 & 8.58 & 7.72 & 2.84 & 2.76 \\
\hline
\end{tabular}


Table 2 Pore structure data of coal fly ash

\begin{tabular}{llll}
\hline Adsorbent & $\mathrm{S}_{\text {BET }}\left(\mathrm{m}^{2} / \mathrm{g}\right)$ & $\mathrm{V}_{\text {total }}\left(\mathrm{cm}^{3} / \mathrm{g}\right)$ & Pore diametor $(\mathrm{nm})$ \\
\hline CFA & 8.84 & 0.016 & 8.07 \\
\hline
\end{tabular}

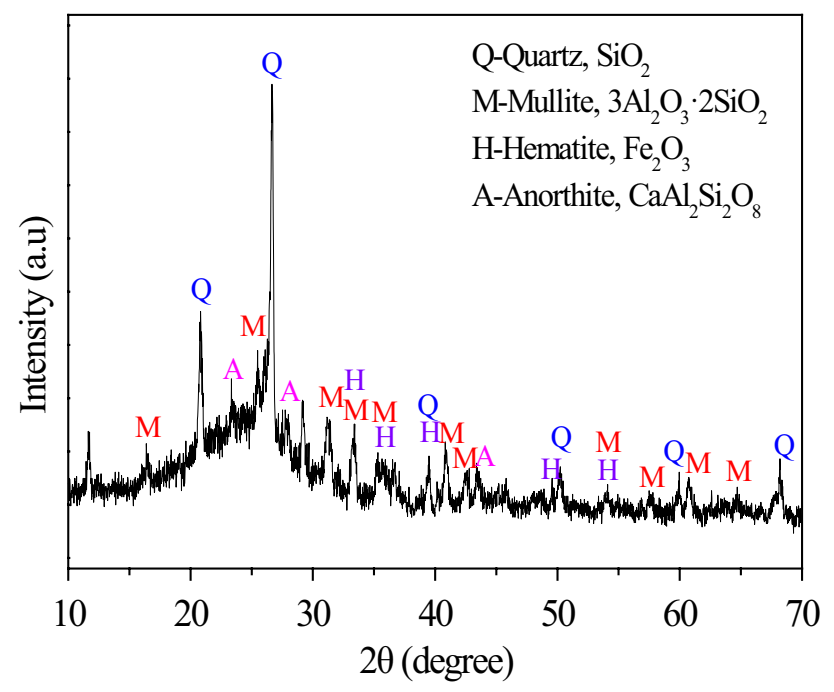

Fig. 1 XRD pattern of the raw coal fly ash

hematite $\left(\mathrm{Fe}_{2} \mathrm{O}_{3}\right)$, and anorthite $\left(\mathrm{CaAl}_{2} \mathrm{Si}_{2} \mathrm{O}_{8}\right)$, which are in agreement with those reported by Mishra [23] and Yilmaz [24]. In addition, amorphous silicate phase was also detected as a broad reflection at $20^{\circ}-30^{\circ}$ in the XRD pattern [25]. The SEM images of the as-received CFA at different magnifications are presented in Fig. 2. The CFA comprises typical glassy spherical-shaped particles as shown in Fig. 2a. It might also be observed that some smaller size particles with various shapes are adhered to bigger size particles (Fig. 2b).

\subsection{Effect of CFA dosage, initial quinoline concentration and contact time}

The influence of adsorbent dosage on the adsorption of quinoline is given in Fig. 3. In case of $0.10 \mathrm{~g}$ CFA dosage, an adsorption capacity of $7.46 \mathrm{mg} / \mathrm{g}$ was acquired, which is comparable with the maximum capacity of $2.1 \mathrm{mg} / \mathrm{g}$ for coking wastewater adsorption [26] and $3.95 \mathrm{mg} / \mathrm{g}$ for Reactive Black 5 adsorption on raw coal fly ash [27]. It can be noticed that the amount of quinoline adsorbed per mass of adsorbent by CFA markedly decreases from 7.46 to $4.95 \mathrm{mg} / \mathrm{g}$ with the increment of adsorbent amount in the range of $0.1-0.4 \mathrm{~g}$. Accordingly, the removal efficiency increases with an increase in adsorbent dosage due to the unsaturation of adsorption sites at higher adsorbent dosages for constant quinoline concentration (not shown). When the amount of CFA is further increased to $0.5 \mathrm{~g}$, the adsorption capacity of CFA for quinoline is slightly reduced to $4.50 \mathrm{mg} / \mathrm{g}$, meaning the slow increase of quinoline removal as both the surface and concentration of quinoline settled to equilibrium with each other [28].

The influence of contact time on quinoline adsorption onto CFA at different initial quinoline concentrations $(20,50$, and $100 \mathrm{mg} / \mathrm{L}$ ) is displayed in Fig. 4. It was observed that the adsorption amount of quinoline increases with the increment of contact time. Particularly, a rapid adsorption occurred during the first $20 \mathrm{~min}$ irrespective of the initial quinoline concentrations, which is most possibly ascribed to the high concentration gradient and lots of vacant sites available during the initial adsorption stage. Since the majority of the exterior sites of the adsorbent surface were occupied with quinoline molecules after the fast adsorption stage, the adsorption began to occur at internal sites of CFA and proceeded gradually until a final equilibrium realized after about

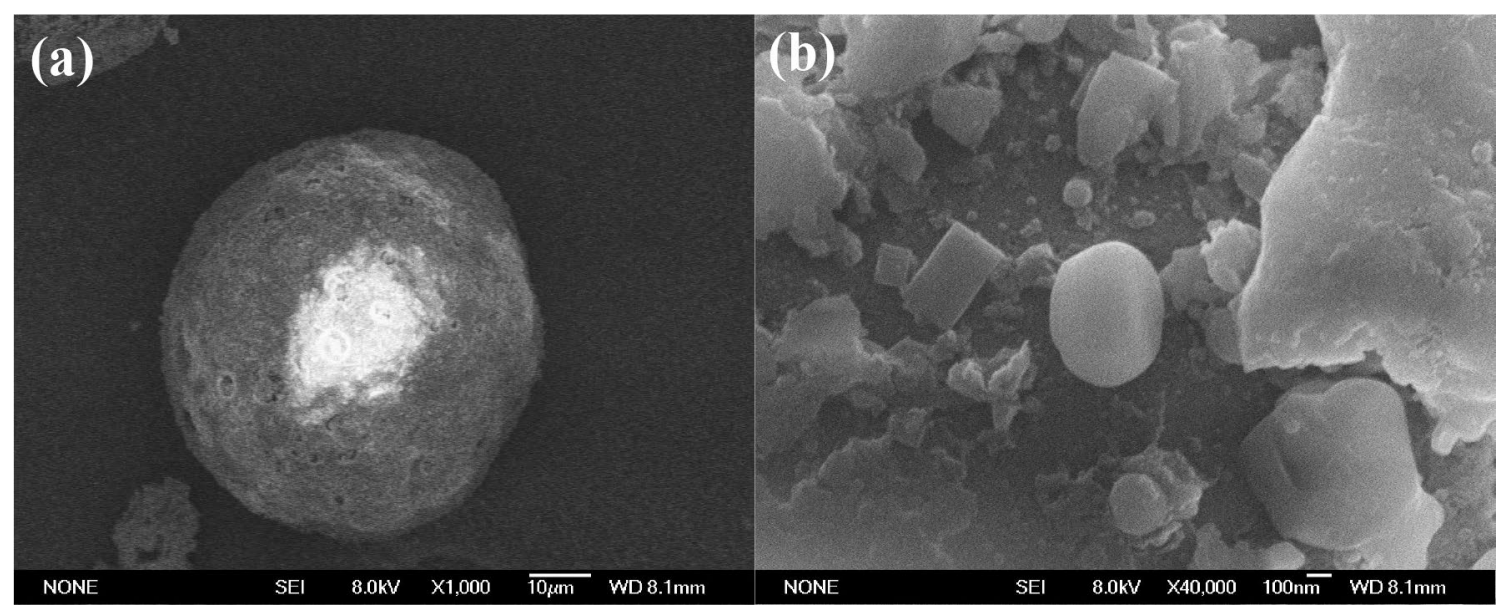

Fig. 2 SEM images of the raw coal fly ash at $\mathbf{a} \times 1000$ and $\mathbf{b} \times 40,000$ 


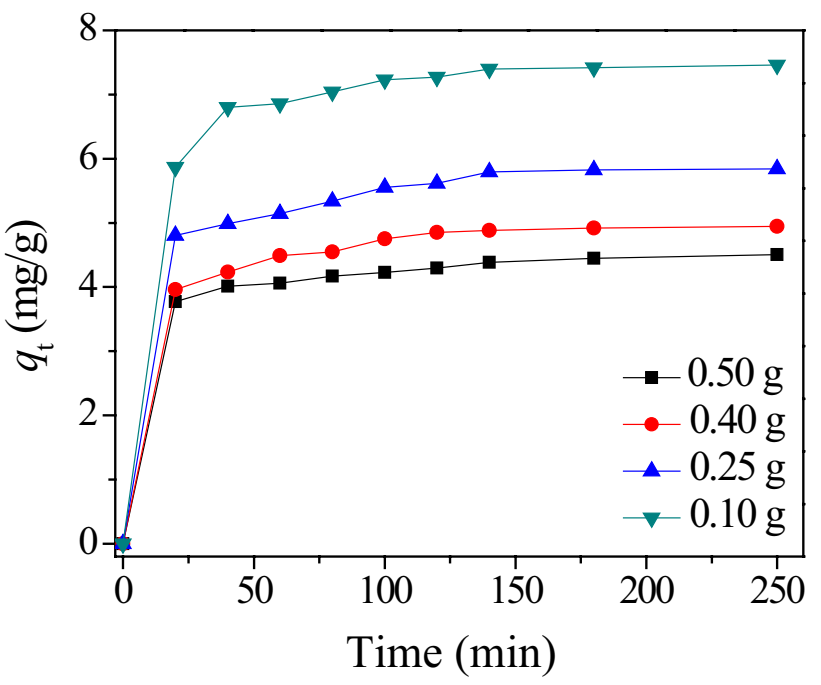

Fig. 3 Effect of adsorbent dosage on adsorption of quinoline onto CFA at $25^{\circ} \mathrm{C}$ (initial quinoline concentration: $50 \mathrm{mg} / \mathrm{L}$ )

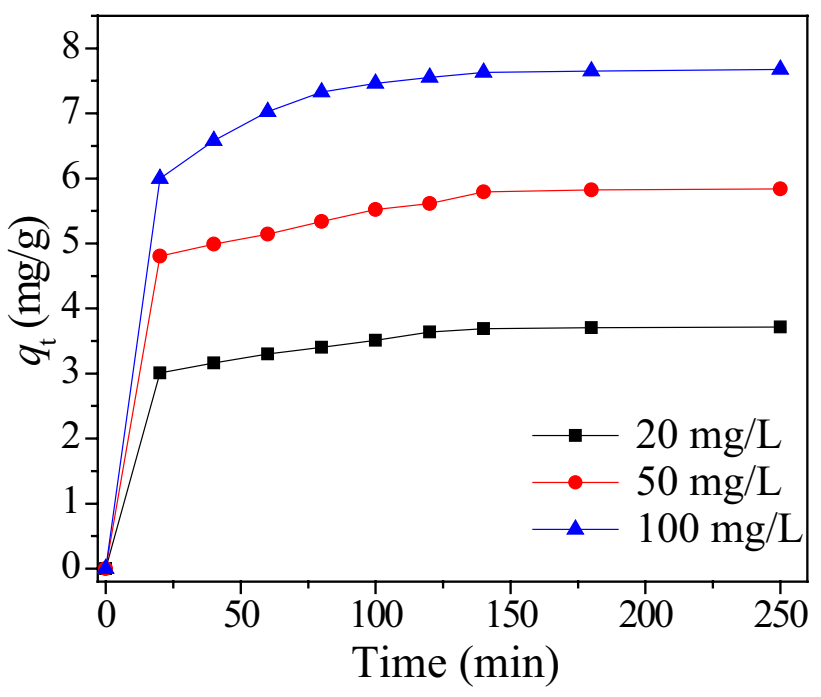

Fig. 4 Effect of contact time and initial concentration on adsorption of quinoline onto CFA at $25^{\circ} \mathrm{C}$ (catalyst dosage: $0.25 \mathrm{~g}$ )

$140 \mathrm{~min}$. At the same time, the continuous reduction in the concentration driving force with the prolonging of contact time also retards the adsorption. Similar result was also reported for the adsorption of quinoline onto different adsorbents in the literature [29]. On the other hand, the adsorption capacity is closely related to the initial quinoline concentration and exhibits a marked increase with the concentration due to higher accessibility of quinoline molecules in the solution for adsorption and concentration gradient for mass transfer between the aqueous phase and the solid phase.

\subsection{Adsorption kinetics}

In this study, three simplified kinetic models (pseudofirst-order, pseudo-second-order and intra-particle diffusion) were applied to correlate the experimental data. The pseudo-first-order (expressed by Eq. (3)) and pseudosecond-order (expressed by Eq. (4)) kinetic models assume that the physical adsorption and chemical adsorption dominate the rate, respectively.

$\ln \left(q_{e}-q_{t}\right)=\ln q_{e}-k_{1} \cdot t$

$\frac{t}{q_{t}}=\frac{1}{k_{2} q_{e}^{2}}+\frac{1}{q_{e}} t$

in which $k_{1}\left(\mathrm{~min}^{-1}\right)$ and $k_{2}(\mathrm{~g} / \mathrm{mg} \mathrm{min})$ are the rate constants, and $q_{\mathrm{t}}$ and $q_{\mathrm{e}}$ represent the amounts of quinoline adsorbed $(\mathrm{mg} / \mathrm{g})$ on adsorbent at the sampling time $t$ (min) and at equilibrium, respectively.

The fitted lines of $\ln \left(q_{e}-q_{t}\right)$ against $t$ for pseudo-firstorder and $t / q_{t}$ versus $t$ for pseudo-second-order kinetic models are shown in Fig. 5a and Fig. 5b, respectively. All the parameters of $q_{e}$ and $k$ as well as correlation coefficient constant $R^{2}$ calculated from the corresponding fitted lines are summarized in Table 3. It is noticeable that the $q_{\mathrm{e}}$ values calculated with the pseudo-second-order kinetic model are much more close to the experimental data. By comparing values of $R^{2}$, it can be concluded that the experimental data are better fitted with the pseudosecond-order model, meaning that the adsorption process is likely to be a chemisorption process, which depended on the chemical character of CFA and quinoline solution. Similar finding with respect to the fit of pseudo-secondorder was provided by researchers on quinoline adsorption onto bamboo charcoal [30], anionic dyes sorption on fly ash [31] Reactive Black 5 adsorption on high lime coal fly ash [27].

The intra-particle diffusion model described by both external and intra-particle diffusions is usually adopted to explore the rate controlling steps involved during adsorption. The intra-particle diffusion model is expressed as follows:

$q_{t}=k_{i} t^{1 / 2}+C$

where $k_{i}$ is the intra-particle diffusion rate constant $\left(\mathrm{mg} / \mathrm{g} \mathrm{min}^{1 / 2}\right.$ ) and the values of $C$ depict the boundary thickness.

To complete the adsorption of quinoline onto CFA, the adsorbate should diffuse from the solution to the external surface and subsequently to the internal surface of the adsorbent (intra-particle diffusion). In our study, the regression of $q_{\mathrm{t}}$ versus $t^{1 / 2}$ shows a bi-linearity nature (Fig. 6), meaning two steps of mass transfer occur during the adsorption process [32, 33]. Obviously, this bi-linearity 

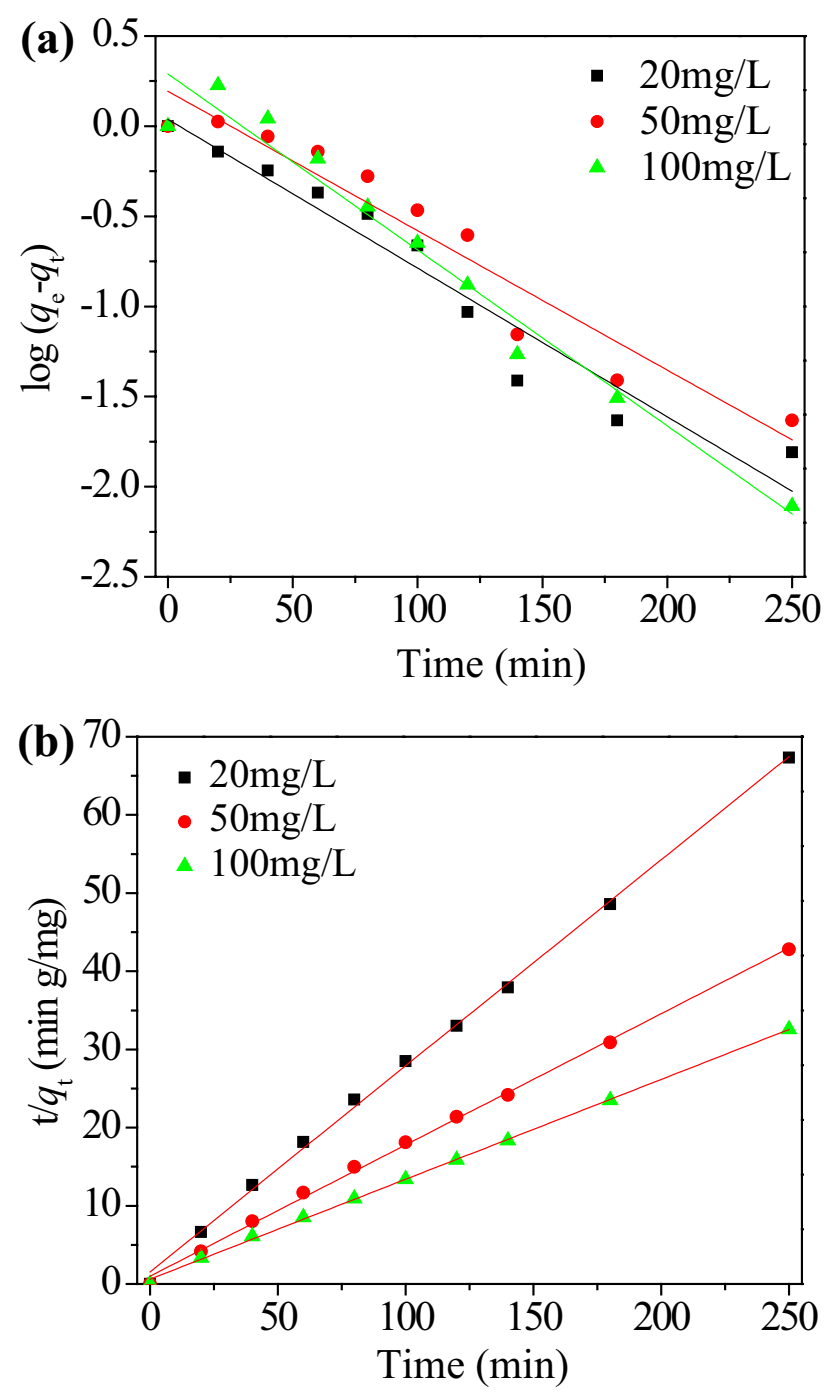

Fig. 5 Linear fit of experimental data using a pseudo-first-order and $\mathbf{b}$ pseudo-second-order kinetic models

became prominent at higher quinoline concentration. From Table 4 , the values of $k_{\mathrm{i}, 1}$ and $k_{\mathrm{i}, 2}$ (the slopes of the two linear portions, respectively) increase with the increment of initial quinoline concentration owing to increase of driving force at higher initial concentrations. The adsorption stage 1 is ascribed to the external mass transfer, corresponding to the easy adsorption of quinoline molecules on exterior sites of CFA. The relatively slow adsorption stage 2 is possibly on account of the low residual adsorbate concentrations after experiencing an external mass transfer process $[34,35]$ and/ or the diffusion of adsorbate molecules into the pores of the adsorbent [36]. As the fitted lines do not pass through origin, it can be assumed that intra-particle diffusion is not the only rate-controlling step [37]. Many researchers have also reported that the adsorption rate is generally determined by both intra-particle diffusion and liquid film diffusion steps $[38,39]$.

\subsection{Adsorption isotherm}

Langmuir, Freundlich and Redlich-Peterson adsorption isotherms are widely used for describing qualitative information about the capacity of various adsorbents and the nature of the solute-surface interactions [40-42]. The Langmuir isotherm assumes structurally homogeneous surface and monolayer adsorption system, which is described by the following equation:

$q_{e}=\frac{K_{L} q_{\max } C_{e}}{1+K_{L} C_{e}}$

where $K_{L}(\mathrm{~L} / \mathrm{mg})$ and $q_{\max }(\mathrm{mg} / \mathrm{g})$ are the constants related to adsorption affinity of the binding sites and adsorption capacity.

The Freundlich model is based on the assumption of heterogeneous surfaces present in the adsorbents, which can describe heterogeneous surfaces and multilayer adsorption systems. The Freundlich isotherm is generally given as follows:

$q_{e}=K_{F} C_{e}^{1 / n}$

where $K_{\mathrm{F}}(\mathrm{mg} / \mathrm{g})$ and $n$ (dimensionless) represent the adsorption capacity and intensity.

The Redlich-Peterson model expressed as Eq. (8) includes three parameters and presents both the Langmuir and Freundlich isotherms.

$q_{e}=\frac{K_{R P} C_{e}}{1+\alpha C_{e}^{\beta}}$
Table 3 Parameters of pseudofirst-order and pseudo-secondorder adsorption kinetic models at different initial quinoline concentrations

\begin{tabular}{|c|c|c|c|c|c|c|c|}
\hline \multirow[t]{2}{*}{$C_{0}(\mathrm{mg} / \mathrm{L})$} & \multirow[t]{2}{*}{$q_{\mathrm{e}, \mathrm{exp}}$} & \multicolumn{3}{|c|}{ pseudo-first order model } & \multicolumn{3}{|c|}{ pseudo-second order model } \\
\hline & & $q_{\mathrm{e}}(\mathrm{mg} / \mathrm{g})$ & $k_{1}(1 / \mathrm{min})$ & $R^{2}$ & $q_{\mathrm{e}}(\mathrm{mg} / \mathrm{g})$ & $\begin{array}{l}k_{2}(\mathrm{~g} / \\
\left.\mathrm{mg} \cdot \min \times 10^{2}\right)\end{array}$ & $R^{2}$ \\
\hline 20 & 3.73 & 1.04 & 0.019 & 0.936 & 3.79 & 4.55 & 0.998 \\
\hline 50 & 5.86 & 1.21 & 0.018 & 0.922 & 5.95 & 2.84 & 0.998 \\
\hline 100 & 7.68 & 1.34 & 0.023 & 0.962 & 7.82 & 2.69 & 0.999 \\
\hline
\end{tabular}




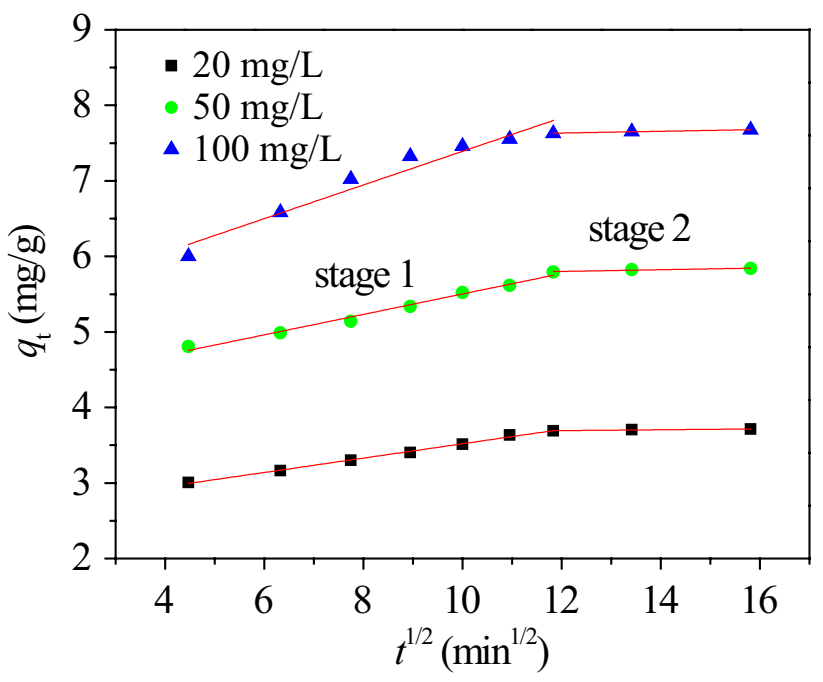

Fig. 6 Linear fit of experimental data using intra-particle diffusion model

Table 4 Intra-particle diffusion rate constants of quinoline adsorption onto coal fly ash

\begin{tabular}{lllll}
\hline$C_{0}(\mathrm{mg} / \mathrm{L})$ & $K_{\mathrm{i}, 1}\left(\mathrm{mg} / \mathrm{g} \mathrm{min}^{1 / 2}\right)$ & $R_{1}^{2}$ & $K_{\mathrm{i}, 2}\left(\mathrm{mg} / \mathrm{g} \mathrm{min} \mathrm{min}^{1 / 2}\right)$ & $R_{2}^{2}$ \\
\hline 20 & 0.095 & 0.996 & 0.00565 & 0.819 \\
50 & 0.135 & 0.986 & 0.01129 & 0.819 \\
100 & 0.223 & 0.939 & 0.01152 & 0.972 \\
\hline
\end{tabular}

where $K_{R P}(\mathrm{~L} / \mathrm{g})$ and a $(\mathrm{L} / \mathrm{mg})^{\beta}$ are Redlich-Peterson isotherm constants, $\beta$ is the exponent which lies between 0 and 1.

Figure 7 shows the equilibrium data of quinoline adsorption onto CFA at different temperatures as well as the nonlinear fits of Langmuir, Freundlich, and Redlich-Peterson isotherm models. The values of isotherm parameters and the determination coefficient $\left(R^{2}\right)$ are listed in Table 5. Obviously, Langmuir isotherm has higher $R^{2}$ values than Freundlich and Redlich-Peterson models. Thus, Langmuir model is more appropriate for describing the adsorption process, indicating the quinoline adsorption occurred at mono-layer and on the homogeneous surface of CFA. This result is similar with that in some previous studies. Hsu [43] reported that the adsorptions of Acid Red 1 onto the raw and modified coal fly ashes could well fit the Langmuir isotherm model.

\section{Conclusions}

The adsorption studies reveal that the adsorption of quinoline on CFA is affected by initial quinoline concentration, contact time and adsorbent dosage. Kinetics studies
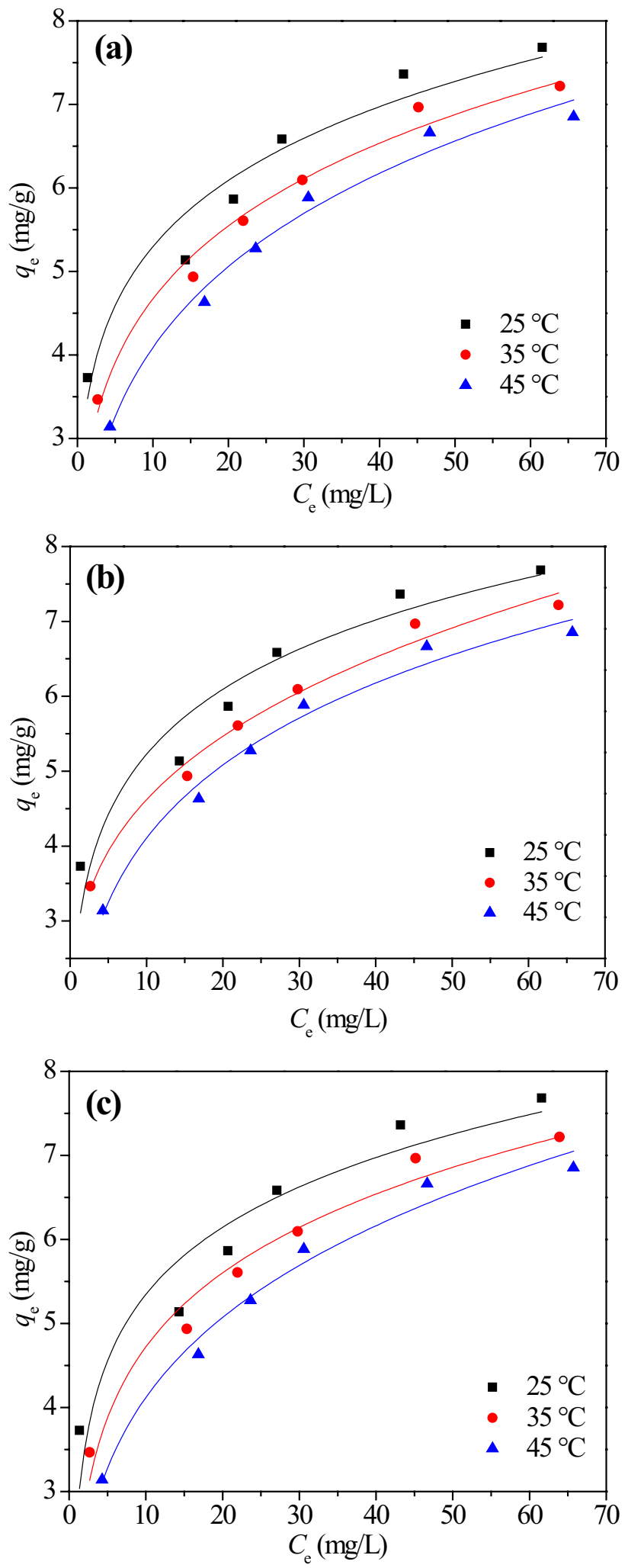

Fig. 7 Nonlinear fits of equilibrium data at different temperatures with a Langmuir, b Freundlich, and c Redlich-Peterson isotherm models

\section{SN Applied Sciences}


Table 5 Isotherm parameters for the adsorption of quinoline onto coal fly ash

\begin{tabular}{|c|c|c|c|c|c|c|c|c|c|c|}
\hline \multirow[t]{2}{*}{$T(\mathrm{~K})$} & \multicolumn{3}{|l|}{ Langmuir } & \multicolumn{3}{|l|}{ Freunhlich } & \multicolumn{4}{|c|}{ Redlich-Peterson } \\
\hline & $K_{\mathrm{L}}(\mathrm{L} / \mathrm{mg})$ & $q_{\max }(\mathrm{mg} / \mathrm{g})$ & $R^{2}$ & $K_{\mathrm{F}}(\mathrm{mg} / \mathrm{g})(\mathrm{l} / \mathrm{g})^{1 / n}$ & $n$ & $R^{2}$ & $K_{R P}(\mathrm{~L} / \mathrm{g})$ & $a$ & $\beta$ & $R^{2}$ \\
\hline 298 & 0.106 & 34.000 & 0.949 & 2.841 & 3.333 & 0.908 & 8.320 & 2.101 & 0.841 & 0.876 \\
\hline 308 & 0.103 & 25.512 & 0.979 & 2.778 & 4.902 & 0.979 & 5.230 & 1.560 & 0.810 & 0.962 \\
\hline 318 & 0.101 & 18.750 & 0.981 & 1.732 & 2.32 & 0.974 & 5.020 & 1.996 & 0.979 & 0.979 \\
\hline
\end{tabular}

indicate that the adsorption complies well with pseudosecond-order and intra-diffusion models, suggesting that the adsorption of quinoline on CFA is a possible chemisorption. It was also found that the Langmuir model can well describe quinoline adsorption isotherm, thus the homogeneous adsorption was speculated to be the main process. Despite relatively low adsorption capacity of the studied fly ash, the use of this adsorbent for wastewater removal is of interest since it is a low-cost and readily available waste. However, to enhance the adsorption capacity of CFA toward quinoline, an effective activation method that does not generate additional pollutants needs to be developed in the future.

Acknowledgements This work was supported by Key Research and Development Plan of Shandong Province (Public Welfare Project, 2017GSF17111), Foundation of State Key Laboratory of High-efficiency Utilization of Coal and Green Chemical Engineering (Grant No. 2017-K31) and Open Foundation of Key Laboratory of Industrial Ecology and Environmental Engineering, MOE (KLEEE-18-09).

\section{Compliance with ethical standards}

Conflict of interest The authors declare that they have no conflict of interest.

\section{References}

1. Xie KC, Li WY, Zhao W (2010) Coal chemical industry and its sustainable development in China. Energy 35:4349-4355

2. Ji Q, Tabassum S, Hena S, Silva CG, Yu G, Zhang Z (2016) A review on the coal gasification wastewater treatment technologies: past, present and future outlook. J Clean Prod 126:38-55

3. Zhu H, Han YX, Xu CY, Han HJ, Ma WW (2018) Overview of the state of the art of processes and technical bottlenecks for coal gasification wastewater treatment. Sci Total Environ 637:1108-1126

4. Liu ZN, Liu Y (2015) Structure and properties of forming adsorbents prepared from different particle sizes of coal fly ash. Chinese J Chem Eng 23:290-295

5. Jing J, Li W, Boyd A, Zhang Y, Colvin VL, Yu W (2012) Photocatalytic degradation of quinoline in aqueous $\mathrm{TiO}_{2}$ suspension. $J$ Hazard Mater 237:247-255

6. Qiao L, Wang JL (2010) Biodegradation characteristics of quinoline by Pseudomonas putida. Bioresour Technol 101:7683-7686

7. Lonappan L, Rouissi T, Das RK, Brar SK, Ramirez AA, Verma M, Surampalli RY, Valero JR (2016) Adsorption of methylene blue on biochar microparticles derived from different waste materials. Waste Manag 49:537-544
8. Pachupate NJ, Vaidya PD (2018) Catalytic wet oxidation of quinoline over Ru/C catalyst. Chem Eng J 6:883-889

9. Singh $L$, Rekha $P$, Chand S (2018) Comparative evaluation of synthesis routes of $\mathrm{Cu} / z e o l i t e \mathrm{Y}$ catalysts for catalytic wet peroxide oxidation of quinoline in fixed-bed reactor. J Environ Manag 215:1-12

10. Wang Y, Tian HL, Yu YG, Hu CZ (2018) Enhanced catalytic activity of a-FeOOH-rGO supported on active carbon fiber (ACF) for degradation of phenol and quinolone in the solar-Fenton system. Chemosphere 208:931-941

11. Zhu H, Ma WC, Han HJ, Han YX, Ma WW (2017) Catalytic ozonation of quinoline using nano-MgO: efficacy, pathways, mechanisms and its application to real biologically pretreated coal gasification wastewater. Chem Eng J 327:91-99

12. Dawood S, Sen TK, Phan C (2014) Synthesis and characterisation of novel-activated carbon from waste biomass pine cone and its application in the removal of Congo red dye from aqueous solution by adsorption. Water Air Soil Poll 225:1818

13. Asl SMH, Javadian H, Khavarpour M, Belviso C, Taghavi M, Maghsudi M (2019) Porous adsorbents derived from coal fly ash as cost-effective and environmentally-friendly sources of aluminosilicate for sequestration of aqueous and gaseous pollutants: a review. J Clean Prod 208:1131-1147

14. Yao ZT, Ji XS, Sarker PK, Tang JH, Ge LQ, Xia MS, Xi YQ (2015) A comprehensive review on the applications of coal fly ash. Earth Sci Rev 141:105-121

15. Ahmaruzzaman M (2009) Role of fly ash in the removal of organic pollutants from wastewater. Energy Fuels 23:1494-1511

16. Ugurlu M, Gurses A, Yalcin M, Dogar C (2005) Removal of phenolic and lignin compounds from bleached kraft mill effluent by fly ash and sepiolite. Adsorption 11:87-97

17. Bada SO, Potgieter JH, Afolabi AS (2013) Kinetics studies of adsorption and desorption of South African fly ash for some phenolic compounds. Part Sci Technol 31:1-9

18. Lin JX, Zhan SL, Fang MH, Qian XQ, Yang H (2008) Adsorption of basic dye from aqueous solution onto fly ash. J Environ Manag 87:193-200

19. Zaharia C, Suteu D (2013) Coal fly ash as adsorptive material for treatment of a real textile effluent: operating parameters and treatment efficiency. Environ Sci Pollut R 20:2226-2235

20. Andersson KI, Eriksson M, Norgren M (2011) Removal of lignin from wastewater generated by mechanical pulping using activated charcoal and fly ash: adsorption isotherms and thermodynamics. Ind Eng Chem Res 50:7722-7732

21. Li HQ, Huang GH, An CJ, Hu JT, Yang SQ (2013) Removal of tannin from aqueous solution by adsorption onto treated coal fly ash: kinetic, equilibrium, and thermodynamic studies. Ind Eng Chem Res 52:15923-15931

22. Zhang CL, Qiao GL, Zhao F, Wang Y (2011) Thermodynamic and kinetic parameters of ciprofloxacin adsorption onto modified coal fly ash from aqueous solution. J Mol Liq 163:53-56

23. Mishra DP, Das SK (2010) A study of physico-chemical and mineralogical properties of Talcher coal fly ash for stowing in underground coal mines. Mater Charact 61:1252-1259 
24. Yilmaz G (2012) Structural characterization of glass-ceramics made from fly ash containing $\mathrm{SiO}_{2}-\mathrm{Al}_{2} \mathrm{O}_{3}-\mathrm{Fe}_{2} \mathrm{O}_{3}-\mathrm{CaO}$ and analysis by FTIR-XRD-SEM methods. J Mol Struct 1019:37-42

25. Cao JJ, Dong XF, Li LL, Dong YC, Hampshire S (2014) Recycling of waste fly ash for production of porous mullite ceramic membrane supports with increased porosity. J Eur Ceram Soc 34:3181-3194

26. Wang NN, Zhang Q, Xu H, Niu WY, Ma L, Han LL, Lan DC (2018) Adsorptive treatment of coking wastewater using raw coal fly ash: adsorption kinetic, thermodynamics and regeneration by Fenton process. Chemosphere 210:624-632

27. Eren Z, Acar FN (2006) Adsorption of Reactive Black 5 from an aqueous solution: equilibrium and kinetic studies. Desalination 194:1-10

28. Tanhaei B, Ayati A, Lahtinen M, Sillanpää M (2015) Preparation and characterization of a novel chitosan/Al2O3/magnetite nanoparticles composite adsorbent for kinetic, thermodynamic and isotherm studies of Methyl Orange adsorption. Chem Eng J 259:1-10

29. Rameshraja D, Srivastava VC, Kushwaha JP, Mall ID (2012) Quinoline adsorption onto granular activated carbon and bagasse fly ash. Chem Eng J 181:343-351

30. Liao P, Yuan SH, Xie WJ, Zhang WB, Tong M, Wang K (2013) Adsorption of nitrogen-heterocyclic compounds on bamboo charcoal: kinetics, thermodynamics, and microwave regeneration. J Colloid Interf Sci 390:189-195

31. Sun DS, Zhang XD, Wu YD, Liu X (2010) Adsorption of anionic dyes from aqueous solution on fly ash. J Hazard Mater 181:335-342

32. Ai LH, Zhang CY, Meng LY (2011) Adsorption of methyl orange from aqueous solution on hydrothermal synthesized Mg-Al layered double hydroxide. J Chem Eng Data 56:4217-4225

33. Shahab KA, Moghaddam A, Reza M (2016) Enhancing the adsorption performance of carbon nanotubes with a multistep functionalization method: optimization of Reactive Blue 19 removal through response surface methodology. Process Saf Environ 99:20-29

34. Lou HL, Cao XZ, Yan X, Wang LN, Chen ZB (2018) Adsorption performance of $\mathrm{Cd}(\mathrm{II}), \mathrm{Cr}(\mathrm{III}), \mathrm{Cu}(\mathrm{II}), \mathrm{Ni}(\mathrm{II}), \mathrm{Pb}(\mathrm{II})$ and $\mathrm{Zn}$ (II) by aminated solution-blown polyacrylonitrile micro/nanofibers. Water Sci Technol 2:378-389

35. Wu FC, Tseng RL, Juang RS (2005) Comparisons of porous and adsorption properties of carbons activated by steam and $\mathrm{KOH}$. J Colloid Interface Sci 283:49-56

36. Dizge N, Aydiner C, Demirbas E, Kobya M, Kara S (2008) Adsorption of reactive dyes from aqueous solutions by fly ash: kinetic and equilibrium studies. J Hazard Mater 150:737-746

37. Arami M, Limaee NY, Mahmoodi NM (2008) Evaluation of the adsorption kinetics and equilibrium for the potential removal of acid dyes using a biosorbent. Chem Eng J 139:2-10

38. Özcan A, Özcan AS (2005) Adsorption of Acid Red 57 from aqueous solutions onto surfactant-modified sepiolite. J Hazard Mater 125:252-259

39. Xu SZ, Lv YL, Zeng XF, Cao DP (2017) ZIF-derived nitrogen-doped porous carbons as highly efficient adsorbents for removal of organic compounds from wastewater. Chem Eng J 323:502-511

40. Novais RM, Caetano APF, Seabra MP, Labrincha JA, Pullar RC (2018) Extremely fast and efficient methylene blue adsorption using eco-friendly cork and paper waste-based activated carbon adsorbents. J Clean Prod 197:1137-1147

41. Uddin $\mathrm{MK}$, Baig U (2019) Synthesis of $\mathrm{CO}_{3} \mathrm{O}_{4}$ nanoparticles and their performance towards methyl orange dye removal: characterisation, adsorption and response surface methodology. J Clean Prod 211:1141-1153

42. $\mathrm{Xu} \mathrm{H}$, Zhang $\mathrm{X}$, Zhang $\mathrm{Y}$ (2018) Modification of biochar by $\mathrm{Fe}_{2} \mathrm{O}_{3}$ for the removal of pyridine and quinoline. Environ Technol 39:1470-1480

43. Hsu TC (2008) Adsorption of an acid dye onto coal fly ash. Fuel 87:3030-3045

Publisher's Note Springer Nature remains neutral with regard to jurisdictional claims in published maps and institutional affiliations. 